\title{
A study of optimal concentration range and time window of sevoflurane preconditioning for brain protection in MCAO rats
}

Ying Deng ${ }^{1 \dagger}$, Chengmei Shi ${ }^{1+}, Y_{i} \mathrm{Gu}^{2}$, Ning Yang ${ }^{1}$, Mao Xu' ${ }^{1}$, Ting $X u^{1}$ and Xiangyang Guo ${ }^{1 *}$

\begin{abstract}
Background: Sevoflurane preconditioning improves brain function in MCAO rats, and there are several methods for determining appropriate concentration and time windows for preconditioning. This study investigated the brain protective effects with a single sevoflurane preconditioning at different concentrations and different time windows on MCAO rats.

Methods: Adult Sprague-dawley rats were randomly assigned to 14 groups. The rats in the sevoflurane preconditioning group inhaled 0.5 MAC, 1.0 MAC, and 1.3 MAC sevoflurane, respectively for $3 \mathrm{~h}$, and then MCAO models were established at $6 \mathrm{~h}, 12 \mathrm{~h}, 24 \mathrm{~h}$, and $48 \mathrm{~h}$. MCAO and sham groups underwent no preconditioning with sevoflurane. The neurological severity score, cerebral infarct volume and brain water content of the rats were measured $24 \mathrm{~h}$ after reperfusion.

Results: After inhalation of 1.3 MAC sevoflurane for $3 \mathrm{~h}$ of preconditioning, the MCAO model was established after $24 \mathrm{~h}$. This preconditioning improved the neurological severity score, reduce cerebral infarct volume and brain water content in MCAO rats. After inhalation of 1.0 MAC sevoflurane for $3 \mathrm{~h}$ of preconditioning, MCAO model established after $24 \mathrm{~h}$ reduced the cerebral infarct volume and brain water content of MCAO rats, but the neurological severity score showed no significant improvement, and no significant brain protective effects were observed at other concentrations and time windows.
\end{abstract}

Conclusions: These results suggested that after inhalation of $1.3 \mathrm{MAC}$ sevoflurane for $3 \mathrm{~h}$ of preconditioning, MCAO model established after $24 \mathrm{~h}$ demonstrated significant brain protective effects in MCAO rats.

Keywords: Sevoflurane, Preconditioning, Cerebral protection, Concentration range, Time window

\footnotetext{
* Correspondence: puthmzk@hsc.pku.edu.cn

${ }^{\dagger}$ Ying Deng and Chengmei Shi contributed equally to this work.

'Department of Anesthesiology, Peking University Third Hospital, No. 49, North Garden Street, Haidian District, Beijing 100191, China

Full list of author information is available at the end of the article
}

(C) The Author(s). 2020 Open Access This article is licensed under a Creative Commons Attribution 4.0 International License, which permits use, sharing, adaptation, distribution and reproduction in any medium or format, as long as you give appropriate credit to the original author(s) and the source, provide a link to the Creative Commons licence, and indicate if changes were made. The images or other third party material in this article are included in the article's Creative Commons licence, unless indicated otherwise in a credit line to the material. If material is not included in the article's Creative Commons licence and your intended use is not permitted by statutory regulation or exceeds the permitted use, you will need to obtain permission directly from the copyright holder. To view a copy of this licence, visit http://creativecommons.org/licenses/by/4.0/ The Creative Commons Public Domain Dedication waiver (http://creativecommons.org/publicdomain/zero/1.0/) applies to the data made available in this article, unless otherwise stated in a credit line to the data. 


\section{Background}

Stroke is the leading cause of disability [1] and is a major cause of morbidity [2], leading to high economic burden worldwide. About $30 \%$ patients die directly due to the disease each year, and similar percentage of sufferers are functionally disabled $[2,3]$.

Ischemic stroke is more commonly seen and is caused by the embolization or thrombosis in blood vessels of the brain, resulting in energy metabolism disorders, ionic homeostasis imbalances and free radical and excitatory neurotoxicity production $[4,5]$. Especially for perioperative ischemic stroke patients, despite its low morbidity [6], it is regarded as a catastrophic event that affects the prognosis and outcomes of surgery.

Currently, the most useful strategy for stroke mainly depends on early detection and thrombolytic therapy $[1$, 7]. However, due to very narrow time window for anticoagulant therapy, many patients miss the best time for effective treatment. Therefore, several recent studies have focused on neuroprotection strategies of stroke $[8$, 9]. These therapeutic approaches have important clinical and social significances in effectively studying the prevention and treatment measures of perioperative stroke.

Preconditioning is an important biological phenomenon that often occurs under non-lethal conditions, such as high temperatures, exercise, systemic or ischemia, inflammation or general anesthesia $[9,10]$. This is defined as delivering a stimulus below the threshold for tissues or organs to develop tolerance to induce subsequent stimuli above the threshold. Preconditioning measures included volatile inhalational anesthetics, hypoxia, ischemia, cortical spreading inhibition, and pro-inflammatory drugs [11]. Preconditioning can induce several internal signaling pathways to protect the body from more severe ischemic damage [12]. Preconditioning with volatile anesthetics induces tolerance to cerebral ischemia/reperfusion injury in animals, and prevents neurologic complications such as perioperative stroke in patients [10]. Sevoflurane is one of the popular inhalational anesthetics that has neuroprotective properties during the perioperative period [11, 12]. Many studies have demonstrated the protective effects of sevoflurane against brain ischemia in vivo and in vitro [4, 13, 14]. Several studies have reported that sevoflurane preconditioning can inhibit oxygen free radicals [14], anti-inflammation [15], activate antioxidant enzymes [11], reduce the expression of apoptosis-related proteins [16], regulate TREK- 1 and TREK- 2 channel $[7,8]$, and inhibit thioredoxin [17], thus reducing nerve injuries associated with middle cerebral artery occlusion (MCAO) in animals.

Current studies have not reached consensus regarding the appropriate concentration and time window of sevoflurane preconditioning. Hence, in the present study, sevoflurane preconditioning was performed at different concentrations and time windows to investigate appropriate concentration and time window regarding the protective effects of sevoflurane preconditioning in ischemia-reperfusion rats. We hypothesized that sevoflurane preconditioning could produce effective brain protective effects in MCAO rats wtih the optimal time window and concentration.

\section{Methods}

\section{Animals}

Male Sprague-Dawley (SD) rats (3 months of age, weighing 330-370 g) (Beijing VitalRiver Laboratory Animial Technology Co.China) were used for experiments in this study. Rats were bred and maintained under standardized housing connditions with food and water ad libitum. The experimental protocol was approved by the Peking University Biomedical Ethics Committee Experimental Animal Ethics Branch (Approval No. LA 2016300).

\section{Establishment of MCAO model}

The MCAO model was established by using the suture method, and induced by sevoflurane inhalation. After anesthesia, a mask inhalation of 1 MAC sevoflurane + $60 \%$ oxygen was performed. During operation, the rectal temperature of the rats was maintained at $36-37^{\circ} \mathrm{C}$. After disinfecting neck, a median of $2 \mathrm{~cm}$ incision and separation were made, the distal right external carotid artery was ligated with a 4-0 surgical suture, and then a proximal slipknot ligation was performed. The common carotid artery and internal carotid artery were blocked with bulldog clamp. An oblique incision was made at the middle segment of the two ligation areas of external carotid artery, followed by the insertion of a thread (ZL400, Guangzhou Xinzan Biotechnology Co., Ltd.), and loosening of the bulldog clamp of the internal carotid artery. The thread was then inserted into the internal carotid artery, pushed to the initial segment of the anterior cerebral artery, and stopped until a resistance was reached, and it was generally not more than $20 \mathrm{~mm}$. The blood supply to the middle cerebral artery was blocked, and the fixed thread for the suture was tightened, a bulldog clamp of the internal carotid artery was loosened, and then a suture was made to the wound. After $120 \mathrm{~min}$, the thread that was exposed outside of the neck skin was gently pulled out and stopped until there was resistance. The excess parts were cut off to recirculate the blood, forming an ischemia-reperfusion model [18].

\section{Experimental methods}

A total of 140 male SD rats were randomly assigned to 14 groups (10 in each group), which were as follows: 0.5 MAC (1\%) sevoflurane $6 \mathrm{~h}, 12 \mathrm{~h}, 24 \mathrm{~h}$, and $48 \mathrm{~h}$ group; 
1.0 MAC (2\%) sevoflurane $6 \mathrm{~h}, 12 \mathrm{~h}, 24 \mathrm{~h}$, and $48 \mathrm{~h}$ group; 1.3 MAC (2.6\%) sevoflurane $6 \mathrm{~h}, 12 \mathrm{~h}, 24 \mathrm{~h}$, and $48 \mathrm{~h}$ group, MCAO group and sham group. Rats were preconditioned with sevoflurane for $3 \mathrm{~h}$. MCAO and sham groups underwent no preconditioning with sevoflurane. The respiratory box was pre-filled with corresponding concentration of sevoflurane (sevoflurane + $60 \%$ oxygen) for $15 \mathrm{~min}$. The rats were then placed in an anaesthetic respiratory box to maintain spontaneous breathing. The corresponding concentration of sevoflurane was continuously blown from the air inlet end, and the air outlet was connected to the atmosphere and the bypass end-expiratory sevoflurane concentration was detected to ensure that the MAC value remains unchanged at 1.3 MAC, 1.0 MAC, and 0.5 MAC. Rats in the sham and MCAO groups just inhaled a mixture of $60 \%$ oxygen and air for $3 \mathrm{~h}$. Physiological parameters of the rats were monitored during preconditioning. The respiratory box was pre-filled with $60 \%$ oxygen, and the rats were placed in a respiratory box for $3 \mathrm{~h}$. The respiratory box was evenly padded with a $37^{\circ} \mathrm{C}$ insulation blanket to keep the rats warm. The MCAO model was established at different time periods $(6 \mathrm{~h} / 12 \mathrm{~h} / 24 \mathrm{~h} / 48 \mathrm{~h})$ after preconditioning. There were 10 rats in each group ( 5 for measuring cerebral infarct volume and 5 for determining brain water content).

Except for these 140 rats, we took another 5 rats in each group of MCAO, Sham, 0.5 MAC, 1.0 MAC and 1.3 MAC respectively to determine whether sevflurane anesthesia caused physiologic side effects.

\section{Neurological severity scores (NSS) [3]}

The neurological severity score was performed $24 \mathrm{~h}$ after MCAO operation in each group by blinding method (scoring was separately performed by two people and averaging). The NSS scoring standard was used with 18 points in total.

\section{The euthanasia}

The rats were induced by sevoflurane inhalation. The respiratory box was pre-filled with $2 \%$ sevoflurane (sevoflurane $+60 \%$ oxygen) for $15 \mathrm{~min}$. The rats were then placed in an anaesthetic respiratory box. The rats were immediately decapitated to take the brains When they were anesthetized and lost consciousness.

\section{Determination of cerebral infarct volume $[19,20]$}

After reperfusion for $24 \mathrm{~h}$, the anesthetized rats with sevoflurane lost consciousness and were decapitated to take the brains, and the olfactory bulb, cerebellum and low brain stem were removed to make into sections. These sections were then placed in $20 \mathrm{ml}$ of $2 \%$ triphenyltetrazolium chloride (TTC, Sigma) staining solution, followed by placing them in a water bath at $37^{\circ} \mathrm{C}$ in dark place, and taken out after 10 min. Normal brain tissues appeared red and the infarct areas remained white. The brain sections were immediately kept in $4 \%$ paraformaldehyde for fixation for $24 \mathrm{~h}$, and pictures were taken with a digital camera. The infarct volume of each section was calculated by using image analysis system Image ProPlus version 6.0. The percentage of cerebral infarct volume was calculated as the (total infarct volume of brain section /total area ofbrain section) $\times 100 \%$.

\section{Determination of brain water content [21]}

Rats were anesthetized with sevoflurane, and immediately decapitated to remove the cerebellum and the lower brain stem. The micro-precision balance was immediately used to weigh the wet weight of the brain, placed in an oven, baked at $100^{\circ} \mathrm{C}$ for $72 \mathrm{~h}$ until constant weight was reached. After weighing the dry weight, the brain water content was calculated by using the formula, water content $(\%)=($ wet weight - dry weight)/wet weight $\times 100 \%$.

\section{General pharmacology and pharmacokinetics}

Sevoflurane is a new type inhalation anesthetic with quick inspiration, rapid induction and fine controllability. Generally associated with stable hemodynamics, dose dependent vasodilatation, and cardiac depression. And could also provide cardioprotection through pharmacologic preconditioning. Sevoflurane was administered through the lung and primarily eliminated by the lungs.

\section{Statistical analysis}

We used Power and Sample Size 14.0 and superiority test method to calculate the sample size. Take $\alpha=0.05$, $\beta=0.9$, according to the values in the literature, the sample size of each group was calculated to be 10 .

Measurement data were expressed as mean \pm standard deviation $(\mathrm{x} \pm \mathrm{s})$. Statistical analysis was performed by using SPSS software, version 17.0. One-way analysis of variance was used for between-group comparison of data with normal distribution. The tukey was used for the post hoc analysis. The between-group comparison of the measurement data with skewed distribution was performed by using Kruskal and wallis method rank sum test, and the bonferroni adjusted method was used to modify the $p$ value. Two-sided $P<0.05$ was considered to be statistically significant.

\section{Results}

Effects of sevoflurane anesthesia on homeostasis of rats After sevoflurane inhalation anesthesia, the righting reflex of the rats was disappeared within a few minutes, and the skin color of the nasolabial and toe ends of each group of rats appeared ruddy, with no significant 
Table 1 Effects of sevoflurane anesthesia on blood gas analysis in rats $(x \pm s, n=5)$

\begin{tabular}{lllll}
\hline Group & $\mathrm{pH}$ & $\mathrm{PaCO}_{2}(\mathrm{mmHg})$ & $\mathrm{PaO}_{2}(\mathrm{mmHg})$ & $\mathrm{Glucose}(\mathrm{mmol} / \mathrm{L})$ \\
\hline MCAO & $7.38 \pm 0.06$ & $37 \pm 3$ & $169 \pm 6$ & $4.9 \pm 0.6$ \\
Sham & $7.43 \pm 0.04$ & $40 \pm 3$ & $158 \pm 10$ & $5.1 \pm 0.6$ \\
0.5 MAC & $7.32 \pm 0.03$ & $38 \pm 4$ & $162 \pm 9$ & $5.2 \pm 0.7$ \\
1.0 MAC & $7.35 \pm 0.05$ & $36 \pm 2$ & $163 \pm 7$ & $5.0 \pm 0.2$ \\
1.3 MAC & $7.33 \pm 0.04$ & $35 \pm 2$ & $159 \pm 8$ & $5.1 \pm 0.4$ \\
\hline
\end{tabular}

fluctuations in $\mathrm{SaO}_{2}$, heart rate and rectal temperature. After anesthesia, the rats were awakened after 5-15 min.

To determine whether sevflurane anesthesia caused physiologic side effects, such as hypoxia, hypercapnia, or hypoglycemia, 5 rats were choosed in MCAO, Sham, 0.5 MAC, 1.0 MAC and 1.3 MAC respectively. MCAO and sham groups underwent no preconditioning with sevoflurane. $2 \mathrm{~mL}$ blood was withdrawn by cardiac puncture at the end of the sevflurane or oxygen exposure. In the MCAO group, $2 \mathrm{~mL}$ blood was withdrawn by cardiac puncture after the establishment of MCAO. Arterial blood gas (ABG) and blood glucose measurements were performed using a portable blood gas analyzer (OPTI Medical Systems, Georgia, USA) and One Touch Ultra blood glucose monitoring system (Life Scan Inc., California, USA) respectively. Those rats were not used for any other part of the study.

The results showed no statistical differences in $\mathrm{pH}$, $\mathrm{PaO}_{2}, \mathrm{PaCO}_{2}$, and blood glucose for each group. No adverse reactions, such as hypoxemia, hypercapnia, and hypoglycemia were observed in each group. These results suggested that the effects of these adverse reactions on behavioral outcomes can be excluded (Table. 1).

\section{Effects of sevoflurane anesthesia on behavioral function score}

The behavioral score for the sham group was $0(0-0)$, and that of the MCAO group was 11.5 (9.0-12.0). The behavioral score for 1.3 MAC sevoflurane preconditioning was
$10.0(7.0-12.0)$ for the $6 \mathrm{~h}$ group, $11.0(10.0-13.0)$ for the $12 \mathrm{~h}$ group, $8.0(6.0-9.0)$ for the $24 \mathrm{~h}$ group, and 11.0 (9.0-13.0) for the $48 \mathrm{~h}$ group. A statistically significant difference was observed between the MCAO group and $24 \mathrm{~h}$ group, but no statistical difference was observed for the comparison of $6 \mathrm{~h}, 12 \mathrm{~h}$, and $48 \mathrm{~h}$ groups $(P=0.390,0.809$, 0.686).

The behavioral score for 1.0 MAC sevoflurane preconditioning was $11.0(8.0-12.0)$ for the $6 \mathrm{~h}$ group, 11.0 (10.0-11.0) for the $12 \mathrm{~h}$ group, $9.5(8.0-10.0)$ for the 24 $\mathrm{h}$ group, and $10.5(8.0-11.0)$ for the $48 \mathrm{~h}$ group. There was no statistical differences between the MCAO group and the $6 \mathrm{~h}, 12 \mathrm{~h}, 24 \mathrm{~h}$, and $48 \mathrm{~h}$ groups $(P=0.809,0.882$, $0.128,0.420$ ).

The behavioral score for $0.5 \mathrm{MAC}$ sevoflurane preconditioning was $10.0(8.0-13.0)$ for the $6 \mathrm{~h}$ group, 10.0 $(9.0-11.0)$ for the $12 \mathrm{~h}$ group, $10.0(10.0-12.0)$ for the $24 \mathrm{~h}$ group, and $9.5(7.0-13.0)$ for the $48 \mathrm{~h}$ group. There was no statistical difference between the MCAO group and the $6 \mathrm{~h}, 12 \mathrm{~h}, 24 \mathrm{~h}$, and $48 \mathrm{~h}$ groups $(P=0.809,0.513$, 0.809, 0.295), (Fig. 1).

\section{Comparison of cerebral infarct volume and percentage of infarct volume after MCAO}

The cerebral infarct volume was $251.22 \pm 57.32 \mathrm{~mm}^{3}$ in the MCAO group, $202.69 \pm 99.34 \mathrm{~mm}^{3}$ in the 1.3 MAC sevoflurane preconditioning $6 \mathrm{~h}$ group, $237.87 \pm 68.01$ $\mathrm{mm}^{3}$ in the $12 \mathrm{~h}$ group, $123.11 \pm 33.29 \mathrm{~mm}^{3}$ in the $24 \mathrm{~h}$ group, and $247.18 \pm 107.91 \mathrm{~mm}^{3}$ in the $48 \mathrm{~h}$ group.

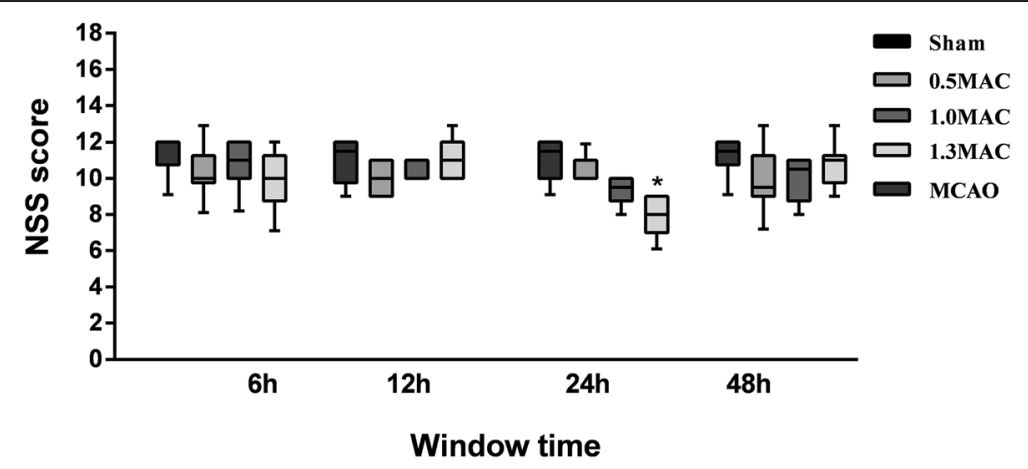

Fig. 1 In 1.3 MAC sevoflurane preconditioning group, the behavioral score was significantly lower than the MCAO group, and showed no statistical difference between others groups and the MCAO group. Values are presented as mean (Lower-Upper limits), $n=10,{ }^{*} p<0.05, \mathrm{vs}$. MCAO group 


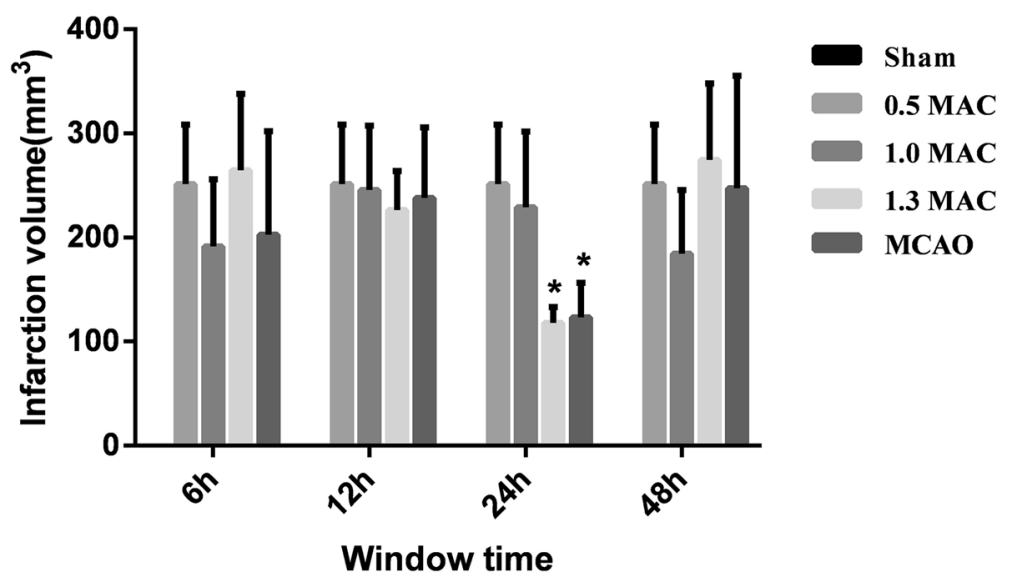

Fig. 2 Comparison with MCAO group showed that the cerebral infarct volume was significantly smaller in 1.3 MAC sevoflurane preconditioning $24 \mathrm{~h}$ group. In $1.0 \mathrm{MAC}$ sevoflurane preconditioning $24 \mathrm{~h}$ group, the cerebral infarct volume was significantly smaller than the MCAO group. There was no statistical difference between others groups and the MCAO group. Values are presented as mean $\pm \mathrm{SD}, n=5,{ }^{*} p<0.05$, vs. MCAO group

There were statistical differences in the $24 \mathrm{~h}$ group $(P=$ 0.002) when compared with MCAO group, while showed no statistical differences with $6 \mathrm{~h}, 12 \mathrm{~h}$, and $48 \mathrm{~h}$ groups $(P=0.245,0.747,0.927)$. The cerebral infarct volume was $264.63 \pm 73.52 \mathrm{~mm}^{3}$ in the $1.0 \mathrm{MAC}$ sevoflurane preconditioning $6 \mathrm{~h}$ group, $226.17 \pm 37.66 \mathrm{~mm}^{3}$ in the $12 \mathrm{~h}$ group, $117.68 \pm 15.36 \mathrm{~mm}^{3}$ in the $24 \mathrm{~h}$ group, and $274.40 \pm 73.49 \mathrm{~mm}^{3}$ in the $48 \mathrm{~h}$ group. When compared with MCAO group, the $24 \mathrm{~h}$ group $(P=0.004)$ showed statistical differences, while no statistical differences were observed with the $6 \mathrm{~h}, 12 \mathrm{~h}$, and $48 \mathrm{~h}$ groups $(P=0.746,0.605,0.600)$. The cerebral infarct volume was $191.38 \pm 64.58 \mathrm{~mm}^{3}$ in the $0.5 \mathrm{MAC}$ sevoflurane preconditioning $6 \mathrm{~h}$ group, $245.36 \pm 62.12 \mathrm{~mm}^{3}$ in the 12 $\mathrm{h}$ group, $228.95 \pm 72.92 \mathrm{~mm}^{3}$ in the $24 \mathrm{~h}$ group, and $184.42 \pm 61.02 \mathrm{~mm}^{3}$ in the $48 \mathrm{~h}$ group. There was no statistical difference with the $6 \mathrm{~h}, 12 \mathrm{~h}, 24 \mathrm{~h}$, and $48 \mathrm{~h}$ groups as compared to the MCAO group $(P=0.180$, 0.894, 0.591, 0.135), (Figs. 2 and 3).
The percentage of infarct volume was $37.89 \pm 7.66 \%$ in the MCAO group, $29.15 \pm 15.68 \%$ in the $1.3 \mathrm{MAC}$ sevoflurane preconditioning $6 \mathrm{~h}$ group, $33.29 \pm 9.33 \%$ in the $12 \mathrm{~h}$ group, $17.01 \pm 5.12 \%$ in the $24 \mathrm{~h}$ group, and $28.63 \pm$ $10.73 \%$ in the $48 \mathrm{~h}$ group. Compared with the MCAO group, a statistically significant difference was observed with the 24 h group $(P=0.001)$, while no statistical difference was observed with the $6 \mathrm{~h}, 12 \mathrm{~h}$, and $48 \mathrm{~h}$ groups $(P=0.152,0.447,0.154)$. The percentage of infarct volume was $35.4 \pm 6.47 \%$ in the 1.0 MAC sevoflurane preconditioning $6 \mathrm{~h}$ group, $34.0 \pm 3.61 \%$ in the $12 \mathrm{~h}$ group, $17.5 \pm$ $2.08 \%$ in the $24 \mathrm{~h}$ group, and $40.5 \pm 11.39 \%$ in the $48 \mathrm{~h}$ group. A statistically significant difference was observed in the $24 \mathrm{~h}$ group $(P=0.003)$, while no statistical difference in the $6 \mathrm{~h}, 12 \mathrm{~h}$, and $48 \mathrm{~h}$ groups when compared with the MCAO group $(P=0.680,0.581,0.685)$. The percentage of infarct volume was $25.8 \pm 8.73 \%$ in the $0.5 \mathrm{MAC}$ sevoflurane preconditioning $6 \mathrm{~h}$ group, $35.3 \pm 11.96 \%$ in the $12 \mathrm{~h}$ group, $36.0 \pm 14.66 \%$ in the $24 \mathrm{~h}$ group, and $27.3 \pm 9.95 \%$

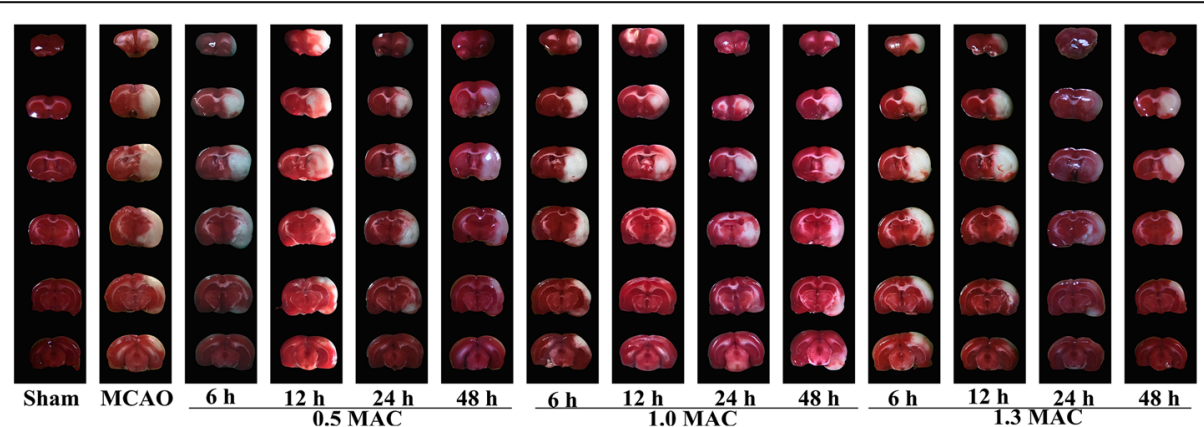

Fig. 3 The red areas represent the normal brain tissues, and the white areas represent the infarction areas. In the 1.3 MAC sevoflurane preconditioning $24 \mathrm{~h}$ group and 1.0 MAC sevoflurane preconditioning $24 \mathrm{~h}$ group, the infarct areas were significantly smaller, especially in the 1.3 MAC sevoflurane preconditioning $24 \mathrm{~h}$ group 


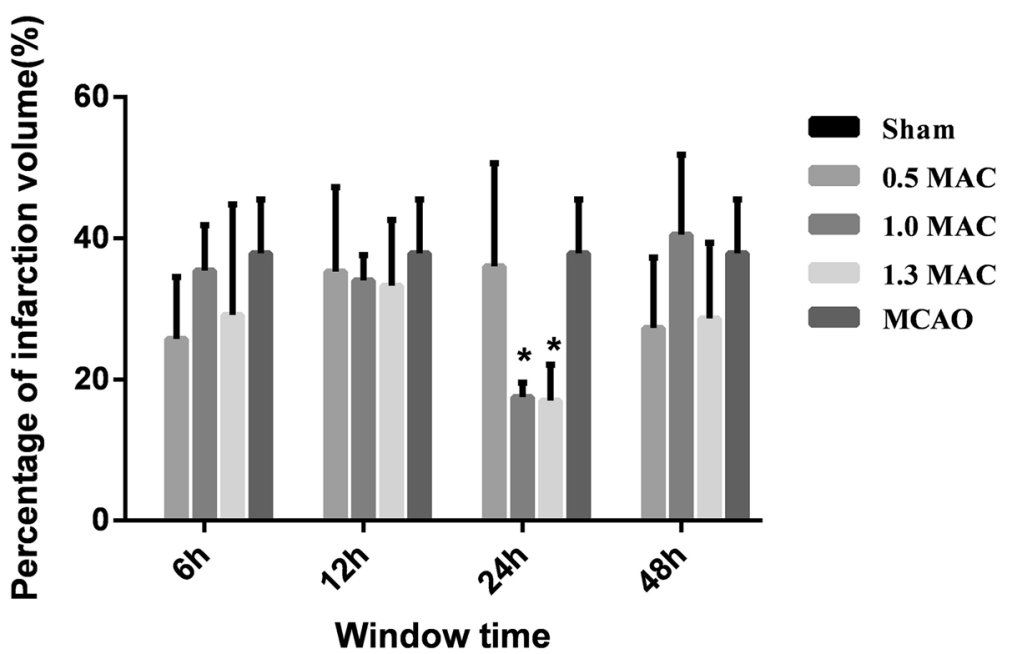

Fig. 4 Comparison with MCAO group, the percentage of infarct volume was significantly lower in the $1.3 \mathrm{MAC}$ sevoflurane preconditioning $24 \mathrm{~h}$ group. In $1.0 \mathrm{MAC}$ sevoflurane preconditioning $24 \mathrm{~h}$ group, the cerebral infarct volume was significantly lower than the MCAO group. There was no statistical difference between other groups and MCAO group. Values are presented as mean $\pm \mathrm{SD}, n=5,{ }^{*} p<0.05$, vs. MCAO group

in the $48 \mathrm{~h}$ group. Comparison with MCAO group showed no statistical difference with the $6 \mathrm{~h}, 12 \mathrm{~h}, 24 \mathrm{~h}$, and $48 \mathrm{~h}$ groups $(P=0.064,0.682,0.754,0.103)$, (Fig. 4).

\section{Determination results of brain water content}

The brain water content was $82.61 \pm 0.48 \%$ in the sham group and $83.29 \pm 0.21 \%$ in the MCAO group, and the difference was statistically significant $(P=0.014)$. The brain water content was $83.32 \pm 0.27 \%$ in the $1.3 \mathrm{MAC}$ sevoflurane preconditioning $6 \mathrm{~h}$ group, $83.49 \pm 0.43 \%$ in the $12 \mathrm{~h}$ group, $82.29 \pm 0.68 \%$ in the $24 \mathrm{~h}$ group, and $83.39 \pm 0.79 \%$ in the $48 \mathrm{~h}$ group. Comparison with MCAO group showed a statistically significant difference with the $24 \mathrm{~h}$ group $(P=0.000)$, while no statistical significance was observed with the $6 \mathrm{~h}, 12 \mathrm{~h}$, and $48 \mathrm{~h}$ groups $(P=0.905,0.456,0.911)$. The brain water content was $83.34 \pm 0.21 \%$ in the $1.0 \mathrm{MAC}$ sevoflurane preconditioning $6 \mathrm{~h}$ group, $83.24 \pm 0.35 \%$ in the $12 \mathrm{~h}$ group, $82.68 \pm 0.62 \%$ in the $24 \mathrm{~h}$ group, and $83.28 \pm 0.11 \%$ in the $48 \mathrm{~h}$ group. Compared with the MCAO group, a statistically significant difference with the $24 \mathrm{~h}$ group $(P=$ 0.027), and no statistical significance with the $6 \mathrm{~h}, 12 \mathrm{~h}$, and $48 \mathrm{~h}$ groups $(P=0.870,0.849,0.977)$ were observed. The brain water content was $83.36 \pm 0.21 \%$ in the 0.5 MAC sevoflurane preconditioning $6 \mathrm{~h}$ group, $82.88 \pm$ $0.43 \%$ in the $12 \mathrm{~h}$ group, $82.91 \pm 0.38 \%$ in the $24 \mathrm{~h}$ group, and $82.81 \pm 0.57 \%$ in the $48 \mathrm{~h}$ group. There was no statistically significant difference with the $6 \mathrm{~h}, 12 \mathrm{~h}, 24 \mathrm{~h}$, and $48 \mathrm{~h}$ groups when compared with the MCAO group $(P=0.812,0.134,0.160,0.099)$, (Fig. 5).

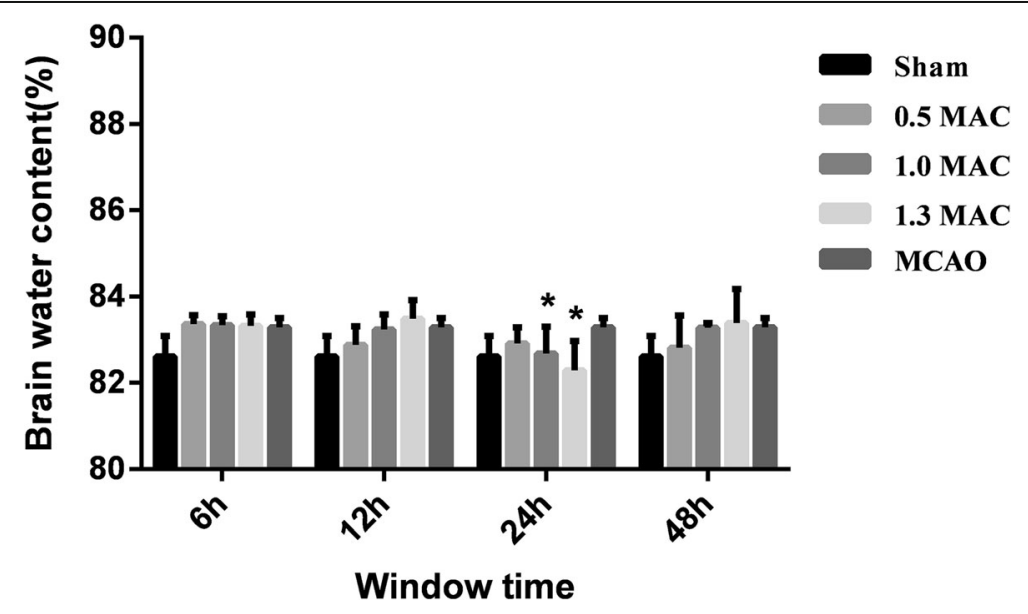

Fig. 5 The brain water content in the 1.3 MAC sevoflurane preconditioning $24 \mathrm{~h}$ group and $1.0 \mathrm{MAC}$ sevoflurane preconditioning $24 \mathrm{~h}$ group was significantly lower than the MCAO group. There was no statistical difference between others groups and the MCAO group. Values are presented as mean $\pm \mathrm{SD}, n=5,{ }^{*} p<0.05$, vs. MCAO group 


\section{Discussion}

This study used a single sevoflurane inhalation method to investigate whether preconditioning with different concentrations of sevoflurance can have brain protective effects. And the primary outcome is cerebral infarct volume. In the present study, after 1.3 MAC sevoflurane preconditioning, the MCAO model established after $24 \mathrm{~h}$ showed significant improving effects on the neurobehavioral score, cerebral infarct volume, and water content of brain tissue for the rats. This indicated that after 1.3 MAC sevoflurane preconditioning for $3 \mathrm{~h}$, MCAO model established after $24 \mathrm{~h}$ showed effective brain protection. Compared with 0.5 MAC and 1.0 MAC preconditioning, the protective effects associated with 1.3 MAC sevoflurane preconditioning were more significant. This suggested that the brain protective effects of sevoflurane preconditioning were concentration depended in the literature [14]. With high concentrations of sevoflurane inhalation, the respiratory and circulatory systems can be inhibited in experimental animals [22], whereas no inhalation of higher concentration of sevoflurane for preconditioning was performed in the present study.

Preconditioning with 1.0 MAC sevoflurane for $3 \mathrm{~h}$ showed a significant improvement in the infarct volume and water content of brain tissues, but no significant improvement was observed in the behavioral score, which was not consistent with that of $2 \%$ sevoflurane inhalation that can effectively produce brain protective effects as reported in the literature. This might be due to differences in the preconditioning ways of sevoflurane [14, 19, 23]. Studies by Shiquan Wang et al. showed that $2 \%$ sevoflurane was inhaled each time for $1 \mathrm{~h}$ for 5 consecutive days for preconditioning, and MCAO model that was established after $24 \mathrm{~h}$ had effective neuroprotection [19]. According to a study by Ralphiel S et al., $30 \mathrm{~min}$ exposure to 1.0 MAC sevoflurane produces early neuroprotection against neuronal injury due to global cerebral ischemia induced by cardiac arrest. Repetitive 1.0 MAC sevoflurane anesthesia $30 \mathrm{~min}$ for 4 consecutive days conferred late neuroprotection effects against ischemic neuronal injury for $24 \mathrm{~h}$ preconditioning [23]. Studies by Qianzi Yang et al. found that 1, 2\%, or 4\% sevoflurane inhalation for 5 consecutive days indicated that sevoflurane preconditioning reduced infarct volume and improved neurobehavioral outcome in a dose-dependent manner by the MCAO model that was established after $24 \mathrm{~h}$ preconditioning. After preconditioning with $4 \%$ sevoflurane, the MCAO model was established had improved neurobehavioral score and showed significant cerebral infarct volume of rats [11].

In the present study, the time window of effective single preconditioning concentration of sevoflurane (1.0 MAC, $1.3 \mathrm{MAC}$ ) was $24 \mathrm{~h}$, but the other time windows $(6,12,48 \mathrm{~h})$ after preconditioning showed no significant brain protective effects, which was consistent with the research results of Ralphiel S [23], Qianzi Yang [11], and Shiquan Wang [17] studies. However, some studies showed that if the MCAO model was established $50 \mathrm{~min}$ after inhalation of 1.0 MAC sevoflurane for preconditioning, $60 \mathrm{~min}$ sevoflurane preconditioning can induce the best neuroprotective effects in rats [24]. Another study also demonstrated that sevoflurane preconditioning can produce brain protective effects immediately after preconditioning [25]. The difference in time window of brain protection after this preconditioning was mainly due to the differences in concentration and time of sevoflurane preconditioning.

There are several mechanisms of brain protection for sevoflurane preconditioning, such as by inhibition of oxygen free radicals [11], anti-inflammation [15], activation of antioxidant enzymes [11], reduction of expression of apoptosis-related proteins [16], regulation of TREK-1 [9] and TREK-2 channel [8], inhibition of thioredoxin [17], etc. However, this study is limited as it considered only the concentration and time window of sevoflurane preconditioning, but the specific mechanism is not studied, which is also our future research direction.

\section{Conclusion}

This study has investigated the appropriate concentration and time window for sevoflurane preconditioning. The results indicated that 1.3 MAC sevoflurane preconditioning for $3 \mathrm{~h}$ can be effective in reducing cerebral infarct volume and providing significantly cecebral protective effects. The optimal concentration was 1.3 $\mathrm{MAC}$, and the optimal time window was $24 \mathrm{~h}$ after precondition.

\section{Acknowledgments}

Not applicable.

\section{Authors' contributions}

XG designed experiments; YD and CS carried out experiments; YG, NY, MX, ans TX analyzed experimental results. YD and CS drafted the manuscript. MX conceived and coordinated the study. All authors have read and approved the final manuscript.

\section{Funding}

This work was supported by grants from the Beijing Natural Science Foundation of China (No. B63531-15), and the National Natural Science Foundation of China (No. 81801070). The consulting fee including design of the study and collection of data, animal fees were supported by the Beijing Natural Science Foundation of China (No. B63531-15). The statistical consulting fee and cost of retouching articles in English were supported by the the National Natural Science Foundation of China (No. 81801070).

Availability of data and materials

The data sets generated during the current study are available from the corresponding author on reasonable request. 


\section{Ethics approval and consent to participate}

The experimental protocol was approved by the Peking University Biomedical Ethics Committee Experimental Animal Ethics Branch (Approval No. LA 2016300).

\section{Consent for publication}

Not applicable.

\section{Competing interests}

The authors declare that they have no competing interests.

\section{Author details}

'Department of Anesthesiology, Peking University Third Hospital, No. 49, North Garden Street, Haidian District, Beijing 100191, China. ${ }^{2}$ Beijing Tiantan Hospital, Capital Medical University, No. 119 South 4th Ring West Road, Fengtai District, Beijing 100160, China.

Received: 17 June 2019 Accepted: 11 March 2020

Published online: 05 April 2020

\section{References}

1. Oshiro AH, Otsuki DA, Hamaji MW, et al. Pulse pressure variation and stroke volume variation under different inhaled concentrations of isoflurane sevoflurane and desflurane in pigs undergoing hemorrhage. Clinics (Sao Paulo). 2015:70(12):804-9.

2. van Eeden M, van Mastrigt GA, Evers SM, van Raak EP, Driessen GA, van Heugten CM. The economic impact of mental healthcare consumption before and after stroke in a cohort of stroke patients in the Netherlands: a record linkage study. BMC Health Serv Res. 2016;16(1):688.

3. Chen J, Sanberg PR, Li Y, et al. Intravenous administration of human umbilical cord blood reduces behavioral deficits after stroke in rats. Stroke. 2001;32(11):2682-8.

4. Codaccioni JL, Velly LJ, Moubarik C, Bruder NJ, Pisano PS, Guillet BA. Sevoflurane preconditioning against focal cerebral ischemia: inhibition of apoptosis in the face of transient improvement of neurological outcome. Anesthesiology. 2009;110(6):1271-8

5. Gauberti M, Obiang P, Guedin P, et al. Thrombotic stroke in the anesthetized monkey (Macaca mulatta): characterization by MRI--a pilot study. Cerebrovasc Dis. 2012;33(4):329-39.

6. Hinohara H, Kadoi Y, Takahashi K, Saito S, Kawauchi C, Mizutani A. Time course of changes in cerebral blood flow velocity after tourniquet deflation in patients with diabetes mellitus or previous stroke under sevoflurane anesthesia. J Anesth. 2011;25(3):409-14.

7. National Institute of Neurological Disorders Stroke rt-PA Stroke Study Group. Recombinant tissue plasminogen activator for minor strokes: the National Institute of Neurological Disorders and Stroke rt-PA Stroke Study experience. Ann Emerg Med. 2005;46(3):243-52

8. Zhao G, Yang L, Wang S, et al. TREK-2 mediates the Neuroprotective effect of Isoflurane preconditioning against acute cerebral ischemia in the rat. Rejuvenation Res. 2019;22(4):325-34

9. Pan L, Yang F, Lu C, Jia C, Wang Q, Zeng K. Effects of sevoflurane on rats with ischemic brain injury and the role of the TREK-1 channel. Exp Ther Med. 2017;14(4):2937-42

10. Zwerus R, Absalom A. Update on anesthetic neuroprotection. Curr Opin Anaesthesiol. 2015;28(4):424-30.

11. Yang $\mathrm{Q}$, Dong $\mathrm{H}$, Deng J, et al. Sevoflurane preconditioning induces neuroprotection through reactive oxygen species-mediated up-regulation of antioxidant enzymes in rats. Anesth Analg. 2011;112(4):931-7.

12. Yang $Q$, Yan W, Li X, et al. Activation of canonical notch signaling pathway is involved in the ischemic tolerance induced by sevoflurane preconditioning in mice. Anesthesiology. 2012;117(5):996-1005.

13. Yu Q, Wang H, Chen J, Gao Y, Liang W. Neuroprotections and mechanisms of inhalational anesthetics against brain ischemia. Front Biosci (Elite Ed). 2010;2:1275-98.

14. Wang H, Shi H, Yu Q, Chen J, Zhang F, Gao Y. Sevoflurane preconditioning confers Neuroprotection via anti-apoptosis effects. Acta Neurochir Suppl. 2016;121:55-61.

15. Ye Z, Guo Q, Wang E. Delayed neuroprotective effect of sevoflurane on the expression of NF-kappaB following transient focal ischemia-reperfusion in rats. Zhong Nan Da Xue Xue Bao Yi Xue Ban. 2010;35(3):262-6.
16. Engelhard K, Werner C, Eberspächer E, et al. Sevoflurane and propofol influence the expression of apoptosis-regulating proteins after cerebral ischaemia and reperfusion in rats. Eur J Anaesthesiol. 2004;21 (7):530-7.

17. Wang S, Li Y, Wei J, Li P, Yang Q. Sevoflurane preconditioning induces tolerance to brain ischemia partially via inhibiting thioredoxin-1 nitration. BMC Anesthesiol. 2018;18(1):171.

18. Wei $X$, Liu H, Sun $X$, et al. Hydroxysafflor yellow a protects rat brains against ischemia-reperfusion injury by antioxidant action. Neurosci Lett. 2005;386(1): 58-62.

19. Swanson RA, Morton MT, Tsao-Wu G, Savalos RA, Davidson C, Sharp FR. A semiautomated method for measuring brain infarct volume. J Cereb Blood Flow Metab. 1990;10(2):290-3.

20. Xing $B$, Chen $H$, Zhang $M$, et al. Ischemic postconditioning inhibits apoptosis after focal cerebral ischemia/reperfusion injury in the rat. Stroke. 2008:39(8):2362-9.

21. Wang Z, Shi XY, Yin J, Zuo G, Zhang J, Chen G. Role of autophagy in early brain injury after experimental subarachnoid hemorrhage. J Mol Neurosci. 2012;46(1):192-202.

22. Ebert TJ, Harkin CP, Muzi M. Cardiovascular responses to sevoflurane: a review. Anesth Analg. 1995;81(6 Suppl):S11-22.

23. Payne RS, Akca O, Roewer N, Schurr A, Kehl F. Sevoflurane-induced preconditioning protects against cerebral ischemic neuronal damage in rats. Brain Res. 2005;1034(1-2):147-52.

24. Qiu C, Sheng B, Wang S, Liu J. Is longer sevoflurane preconditioning neuroprotective in permanent focal cerebral ischemia. Neural Regen Res. 2013:8(23):2126-33.

25. Hartmann A, Fassini A, Scopinho A, et al. Role of the endocannabinoid system in the dorsal hippocampus in the cardiovascular changes and delayed anxiety-like effect induced by acute restraint stress in rats. J Psychopharmacol. 2019;33(5):606-14.

\section{Publisher's Note}

Springer Nature remains neutral with regard to jurisdictional claims in published maps and institutional affiliations.

Ready to submit your research? Choose BMC and benefit from:

- fast, convenient online submission

- thorough peer review by experienced researchers in your field

- rapid publication on acceptance

- support for research data, including large and complex data types

- gold Open Access which fosters wider collaboration and increased citations

- maximum visibility for your research: over $100 \mathrm{M}$ website views per year

At BMC, research is always in progress.

Learn more biomedcentral.com/submissions 